\title{
Experimental Study on Carbonation of Steel Fiber Reinforced Concrete
}

\author{
Yan Wang \\ Material Science and Engineering Centers for Post-doctoral Studies, \\ Xi'an University of Architecture and Technology \\ Key Laboratory of New Technology for Construction of Cities in Mountain Area in Chongqing University \\ Ditao Niu and Zhenping Dong \\ School of Civil Engineering, X'an university of Architecture and Technology
}

\begin{abstract}
With the steel fiber reinforced concrete (SFRC) used more and more widely in some large-span structures, large tunnel linings, dam structures, military engineering, and some other major projects, its durability arouses more and more concerns. In this paper carbonation test of SFRC was conducted. The rule for the mixing amount of steel fiber $(0,0.5,1.0,1.5$, and $2.0 \%)$ to affect the carbonation depth of concrete and the strength developing rule of SFRC after carbonation test were researched. To analyze the property change rules from micro perspective of SFRC after carbonation, the pore structure of SFRC after carbonation was tested. The results show that appropriate amount of steel fiber can retard the speed of concrete carbonation; the concrete carbonation speed is the slowest when the fiber content is $1.5 \%$, and the carbonation speed is accelerated when the fiber content is increased to $2 \%$. Carbonation can change the pore structure of SFRC, total porosity, total pore volume, and total pore areas reduced and makes the pore structure of concrete going more reasonable. Carbonation can improve the splitting tensile strength of SFRC to certain extent.
\end{abstract}

Keywords: carbonation, pore structure, steel fiber reinforced concrete, splitting tensile strength.

\section{INTRODUCTION}

Steel corrosion is one of the main factors that affect concrete durability, while in general atmospheric environment the concrete carbonation is the main cause reason of steel corrosion. With the gradual application of steel fiber reinforced concrete (SFRC) in various engineering, its carbonation resistance arouses more and more concerns. The scholar conducted a lot of acceleration tests and exposure tests. Kosa and Naaman (1990) adopt acceleration corrosion test to research the influence of carbonation on the mechanical property of SFRC. Mangat and Gurusamy (1988a, b) studied the carbonation resistance of SFRC in seawater and sewage through exposure test. Xiaobin Wu, Danying Gao, Huimin Pan, and Pengfei Zhao studied the influence of steel fiber on concrete carbonation resistance property through acceleration test. All these researches came to the same conclusion: steel fiber can improve the carbonation resistance of concrete. However, this qualitative conclusion is obviously insufficient to durability design and service life prediction to SFRC structure. It is required to deeply discuss and research on how the steel fiber content affects the carbonation resistance of concrete, and others. For this purpose, the paper will conduct acceleration carbonation test of SFRC, and study on the rule for the content of steel fiber $(0,0.5,1.0,1.5,2.0 \%)$ to affect the carbonation depth of matrix concrete.

\section{EXPERIMENTAL}

\subsection{Concrete composition}

The steel fiber with length of $30 \mathrm{~mm}$, diameter of $0.5 \mathrm{~mm}$, length-diameter ratio of 60 and tensile strength of $>380 \mathrm{MPa}$ is produced by Chongqing Yizhu Building (Group) Co., Ltd. The basic performance and main chemical component of the cement (Qinling Brand P.O 42.5R ordinary Portland cement) are listed in Table 1. Bahe natural river sand and calcareous gravel produced in Jingyangkou Town are used. The fineness modulus of sand is 2.7 , and the mud content is $1.1 \%$. The grain diameter of calcareous gravel is $5-20 \mathrm{~mm}$, and the crushing value index is $6 \%$. The high efficiency water-reducer with mixing proportion of $0.55 \%$ is from Shaanxi Ruide Building Materials Technology Co., Ltd. Five concrete mixing proportions are adopted with water-to-cement ratio of 0.45 and steel fiber volume proportions $\rho$ of $0,0.5,1,1.5$, and $2 \%$ (as shown in Table 2). 
Table 1. PO 42.5R Portland cement property.

\begin{tabular}{|c|c|c|c|c|c|c|c|c|c|c|}
\hline \multicolumn{2}{|c|}{$\begin{array}{l}\text { Splitting tensile } \\
\text { strength }(\mathrm{MPa})\end{array}$} & \multicolumn{2}{|c|}{$\begin{array}{l}\text { Compressive } \\
\text { strength (MPa) }\end{array}$} & \multirow[t]{2}{*}{$\begin{array}{c}\text { Loss on } \\
\text { ignition }(\%)\end{array}$} & \multirow[t]{2}{*}{$\begin{array}{c}\mathrm{MgO} \\
(\%)\end{array}$} & \multirow[t]{2}{*}{$\begin{array}{l}\mathrm{SO}_{3} \\
(\%)\end{array}$} & \multicolumn{2}{|c|}{$\begin{array}{l}\text { Setting time } \\
(\min )\end{array}$} & \multirow[t]{2}{*}{$\begin{array}{c}\text { Fineness } \\
\left(\mathrm{m}^{2} / \mathrm{kg}\right)\end{array}$} & \multirow[t]{2}{*}{$\begin{array}{c}\text { Cement } \\
\text { soundness }\end{array}$} \\
\hline 3 days & 28 days & 3 days & 28 days & & & & Initial setting & Final setting & & \\
\hline 4.3 & 8.1 & 26.1 & 48.5 & 2.7 & 2.3 & 2.4 & 136 & 213 & 358 & Qualified \\
\hline
\end{tabular}

Table 2. Mixing proportion and mechanical property of the SFRC.

\begin{tabular}{|c|c|c|c|c|c|}
\hline Concrete & PC & SFRC-0.5 & SFRC-1.0 & SFRC-1.5 & SFRC-2.0 \\
\hline Cement $\left(\mathrm{kg} / \mathrm{m}^{3}\right)$ & 367 & 367 & 367 & 367 & 367 \\
\hline Sand $\left(\mathrm{kg} / \mathrm{m}^{3}\right)$ & 765 & 735 & 733 & 718 & 702 \\
\hline Calcareous gravel $\left(\mathrm{kg} / \mathrm{m}^{3}\right)$ & 1146 & 1102 & 1100 & 1066 & 1053 \\
\hline Steel fiber volume proportion (\%) & 0 & $0.5 \%$ & $1 \%$ & $1.5 \%$ & $2 \%$ \\
\hline Steel fiber amount $\left(\mathrm{kg} / \mathrm{m}^{3}\right)$ & 0 & 39 & 78 & 117 & 156 \\
\hline Slump (mm) & 110 & 112 & 87 & 47 & 15 \\
\hline \multicolumn{6}{|l|}{ 28-day strength (MPa) } \\
\hline Compressive strength & 37.9 & 38.3 & 39.5 & 40.7 & 35.2 \\
\hline Splitting tensile strength & 6.1 & 8.1 & 9.2 & 11.2 & 7.2 \\
\hline Flexural strength & 5.0 & 5.3 & 6.5 & 7.2 & 9.8 \\
\hline
\end{tabular}

\subsection{Testing method}

The carbonation depth test specimen is $100 \mathrm{~mm} \times 100 \mathrm{~mm} \times 300 \mathrm{~mm}$, and the strength test specimen is $100 \mathrm{~mm} \times 100 \mathrm{~mm} \times 100 \mathrm{~mm}$. Before the test, the specimen is dried in dryer for $48 \mathrm{~h}$ at $60^{\circ} \mathrm{C}$, and then the end of specimen is sealed by heated paraffin. Finally, the specimen is placed in carbonation box with the spacing of $50 \mathrm{~mm}$ at least. When the specimen is carbonized for $3,7,14,28$, and 56 days, the specimen is cut to test for carbonation depth. Specific method: the specimen is cut by rock cutter from one end, with the cutting thickness of $30 \mathrm{~mm}$ for each time. After the cut the specimen is sealed by paraffin, and the specimen is placed in carbonation box again for carbonation. One group specimen is used for strength test each time, and the rest is placed in the carbonation box for carbonation again.

The carbonation depth is measured to $0.01 \mathrm{~mm}$, the mean value of the carbonation depth of three specimens is used as the carbonation depth, and calculated to $0.01 \mathrm{~mm}$. The formula of carbonation depth is as follows:

$$
x=\sum_{j=1}^{3}\left(\sum_{i=1}^{n} x_{i} / n\right) / 3
$$

To observe the internal micro-structure change of SFRC, MIP was used to test the micropore structure of SFRC. In the MIP test, the automatic particle and porous material characterization mercury injection apparatus PoreMaste GT60 produced by Quantachrome was adopted. The sample for the MIP was directly collected from the Splitting tensile sample.

\section{RESULTS AND ANALYSIS}

\subsection{Carbonation depth results and analysis}

The relationship between the lateral carbonation depth of specimen and steel fiber content is shown in Figure 1. When the steel fiber content is $0-1.5 \%$, with the increase of steel fiber, the concrete carbonation depth will be gradually reduced; when the steel fiber content is increased to $2.0 \%$, the concrete carbonation depth will be increased. When steel fiber content is in the appropriate range, the fibers will be evenly distributed in the concrete. Owing to the crack resistance of steel fiber, the original fine crack between aggregate and mortar will be reduced, which can improve the micropore structure of matrix concrete, and make the internal structure of concrete more compacted, so as to inhibit or retard $\mathrm{CO}_{2}$ from spreading in the concrete, reduce the carbonation speed, and reduce the carbonation depth at the same carbonation age. When the mixing amount of steel fiber exceeds certain limitation, the contact between steel fiber and matrix concrete forms more weak binding interfaces, which makes $\mathrm{CO}_{2}$ easy to spread in the concrete and increases the concrete carbonation depth.

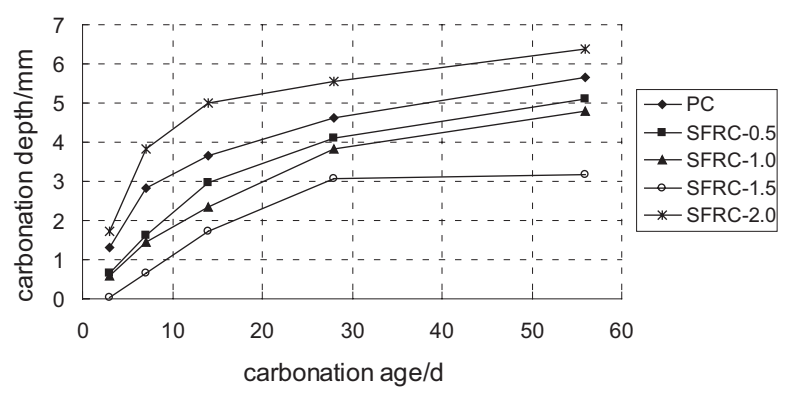

Figure 1. Carbonation depth curves of SFRC with different fiber content (lateral). 
After concrete carbonation steel fiber influence coefficient, the carbonation depth of SFRC can be expressed in following formula:

$$
x_{\rho}=K_{\rho} K \sqrt{t}=K_{\rho} x
$$

where $X_{\rho}$ is the concrete carbonation depth when steel fiber content is $\rho$;

$K_{\rho}$ is the concrete carbonation steel fiber influence coefficient when steel fiber content is $\rho$;

Therefore,

$$
K_{\rho}=\frac{x_{\rho}}{x}
$$

$K_{\rho}$ is calculated according to the lateral carbonation depth value of SFRC, as shown in Figure 2. The relationship between steel fiber influence coefficient and fiber content can be obtained through regression analysis of the value:

$$
\begin{aligned}
K_{\rho}= & 0.634 \rho^{3}-1.496 \rho^{2}+0.594 \rho \\
& +0.980(r=0.8622)
\end{aligned}
$$

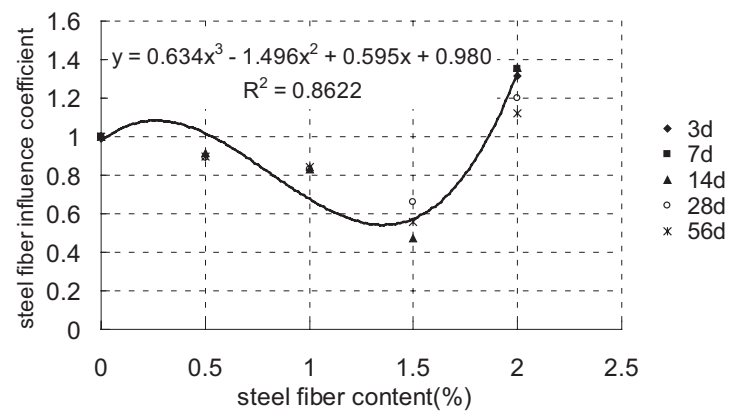

Figure 2. The relationship curve between steel fiber content and $\mathrm{K}_{\rho}$.

In the test, it is found that the carbonation depths on different sides of the test piece of SFRC are obviously different. However, there is consistent rule, the top side has the maximum carbonation depth, followed by lateral side, and the bottom has the minimum carbonation depth. In the casting and vibration of concrete test piece, the coarse aggregate sinks, gel material floats, which makes the bottom of test piece compacted, the top side has much floating mortar, with poor compactness, while the compactness of lateral side is even as compared to the bottom and top side of the test piece. Therefore, the carbonation depth on the top of test piece is the greatest, followed by lateral side, and the least at the bottom.

Sample data of 24 groups in the test are used for analysis, the results show that carbonation depths of top side is $1.31 \times$ the lateral side, while bottom carbonation depths of bottom side is $0.52 \times$ the lateral side.

\subsection{Results and analysis of splitting tensile strength}

The research shows that the influence of steel fiber content on the compressive strength of concrete is slight. However, it can stop the fine crack inside concrete from spreading and retard the occurrence and development of macro-crack, and can obviously improve concrete tensile strength. Therefore, the article chooses to research on the influence of carbonation on the splitting tensile strength of concrete. The influence coefficient $R$ on the splitting tensile strength of SFRC:

$$
f_{\mathrm{fc}, \mathrm{spl}}^{\mathrm{c}}=R f_{\mathrm{fc}, \mathrm{spl}}
$$

where $f_{\mathrm{fc}, \mathrm{spl}}$ and $f_{\mathrm{fc}, \mathrm{spl}}^{\mathrm{c}}$ denote splitting tensile strength of SFRC before and after carbonation.

After carbonized for $3,7,14,28$, and 56 days, the carbonation depth is tested. The change curve of influence coefficient of splitting tensile strength of SFRC after carbonation is shown in Figure 3.

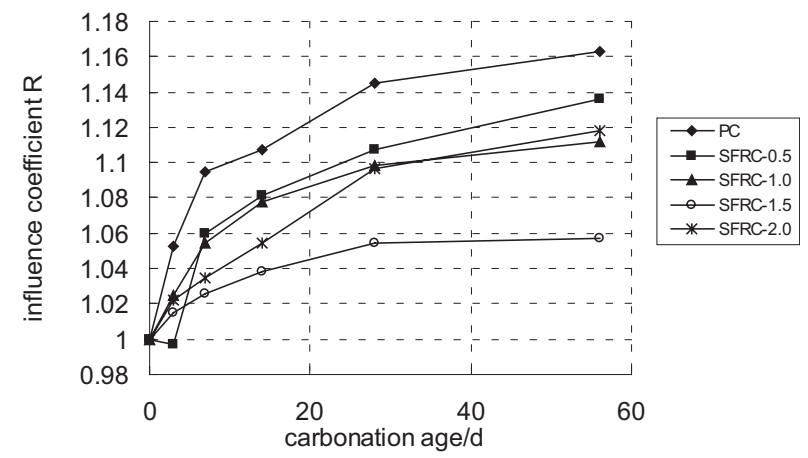

Figure 3. The relationship curve between steel fiber content and $R$.

The figure shows that $R$ presents a rising tendency, which indicates that with the growth of carbonation age, the splitting tensile strength of SFRC is improved. The cause for the increased splitting tensile strength of SFRC mainly includes: first, after concrete carbonation, the chemical component and pore structure of concrete base change, calcium hydroxide and $\mathrm{CO}_{2}$ have reaction and generate water insoluble calcium carbonate, and the calcium carbonate is filled in the gel pore, capillary pore, and fine crack inside the concrete. With the increase of carbonation age, the carbonation depth will be greater, the porosity of concrete at carbonation layer will be reduced and the compactness will be improved; on the other hand, carbonation reinforces the interface layer between steel fiber and cement base. The water-binder ratio of SFRC is the same, the concrete compactness improvement at carbonation layer is consistent, and the increase degree of splitting tensile strength is mainly decided by the concrete carbonation depth. Ordinary concrete is carbonized as the fastest, the increase speed of splitting strength is higher than that of SFRC. The greater the mixing amount of steel fiber 
is, the slower the carbonation will be, the concrete with the $1.5 \%$ fiber content is carbonized the slowest, and the increase of splitting tensile strength is the least. Through fast carbonation for 56 days, the increase of splitting tensile strength of concrete will reach $16.3 \%$, while the increase of splitting tensile strength of the concrete with the mixing amount of steel fiber of $1.5 \%$ is only $5.7 \%$.

\subsection{Micropore structure analysis}

The relationship between the pore diameter and concrete performance is evaluated and analyzed by the academician Zhongwei Wu according to the division standard: harmless pore $(<20 \mathrm{~nm})$, less-harm pore $(20-50 \mathrm{~nm})$, harmful pore $(50-200 \mathrm{~nm})$ and muchharm pore $(>200 \mathrm{~nm})$. Refer to the pore distribution curve of carbonized SFRC in Figures 4 and 5.

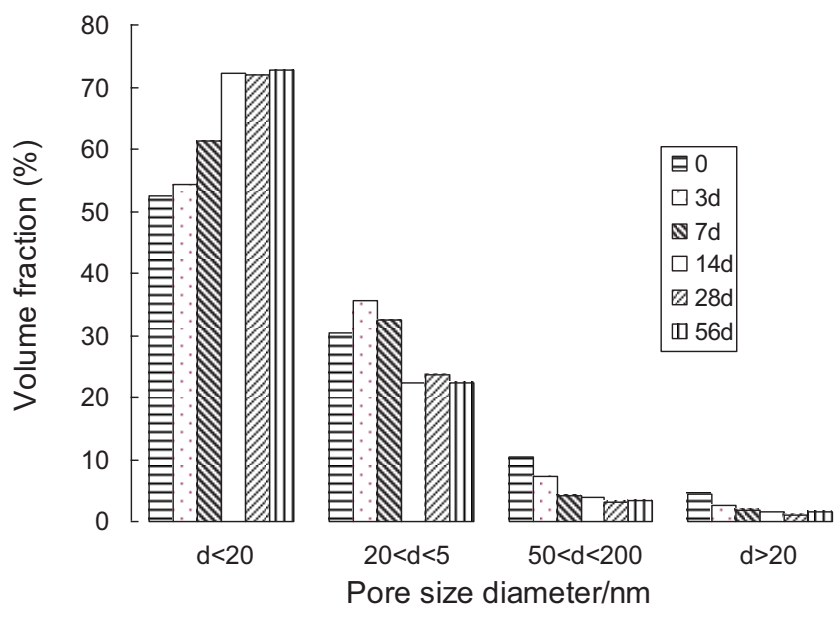

Figure 4. Pore size distribution histograms of SFRC-1.5.

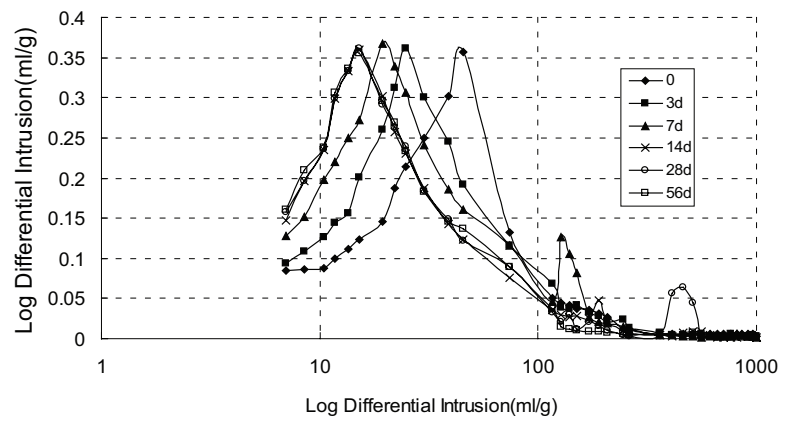

Figure 5. Pore size distribution differential curves of SFRC-1.5.

(1) Carbonation changes the pore structure of SFRC, reduces total porosity, total pore volume and area, and makes the pore structure of concrete base better. Owing to the limitation of sampling size in the test, samples with fast carbonation for 3 and 7 days, the complete carbonation area and local carbonation area coexist, and the pore structure of the sample changes continuously, and the result shows that the pore structure of the sample carbonized for 14 days has become stable, and can be deemed that the test sample has been completely carbonized. In complete carbonation, the total porosity of concrete is reduced by $24.11 \%$, the total pore volume, area are reduced by 14.52 and $16.32 \%$, respectively. The mean pore diameter and most probable pore diameter present reducing tendency, and the overall mercury penetration curve moves to the left.

(2) After carbonation, the volume fraction of pore diameter $d<20 \mathrm{~nm}, 20 \mathrm{~nm} \leq d<50 \mathrm{~nm}$ is increased, at early period of carbonation, the volume fraction of $20 \mathrm{~nm} \leq d<50 \mathrm{~nm}$ is increased, in complete carbonation, the volume fraction of $d<20 \mathrm{~nm}$ is obviously increased, while the volume fraction of $20 \mathrm{~nm} \leq d<50 \mathrm{~nm}$ is reduced. The volume fraction of pore diameter $50 \mathrm{~nm} \leq d<200 \mathrm{~nm}$, $d \geq 200 \mathrm{~nm}$ is obviously reduced. Harmless pre, less-harm pore or micro-pore are increased in the concrete, the proportion of harmful pore, much-harm pore is reduced, the pore structure is improved, the compactness of original concrete is improved, and the concrete strength is improved from macrocosmic perspective.

\section{CONCLUSIONS}

(1) Appropriate amount of steel fiber can retard the speed of concrete carbonation, the concrete carbonation speed is the slowest when the mixing amount is $1.5 \%$, and the carbonation speed is accelerated when the mixing amount is increased to $2 \%$. The casting side can affect the carbonation speed of SFRC, the top side has the fastest carbonation, followed by lateral side, and the bottom has the slowest carbonation.

(2) Carbonation can improve the splitting tensile strength of SFRC to certain extent.

(3) Carbonation can change the pore structure of SFRC, total porosity, total pore volume, and total pore area reduced, and make the pore structure of concrete going more reasonable.

\section{ACKNOWLEDGMENTS}

This research is financially supported by the National Science Foundation of China (Grant No. 51380445), the National Science Foundation of Shan'xi Province China (Grant No. 2013JQ7033), and Visiting Scholar Foundation of Key Laboratory of New Technology for Construction of Cities in Mountain Area In Chongqing University. 


\section{REFERENCES}

Haitang, Z., \& Danying, G. (2005). Test research on basic properties of steel fiber reinforced concrete under carbonation. Journal of Zhengzhou University (Engineering Science), 26(1), 5-8.

Kosa, K., \& Naaman, A. E. (1990). Corrosion of steel fiber reinforced concrete. ACI Materials Journal, 87(1), 27-37.

Mangat, P. S., \& Gurasamy, K. (1988a). Chloride diffusion in steel fiber reinforced marine concrete. Cement and Concrete Research, 17(3), 385-396.

Mangat, P. S., \& Gurusamy, K. (1988b). Long term properties under marine exposure of steel fibre reinforced concrete containing PFA. Materials and Structures, 21, 352-358.

Pengfei, Z., \& Qiaowei, B. (2008). Experimental study on the mechanics properties and durability of hybrid crude fiber reinforced light-weight aggregate concrete. Bulletin of the Chinese Ceramic Society, 27(4), 852-856.

Xiaobin, W., \& Zhixing, Z. (2009). Experimental research on steel fiber-ceramic concrete carbonation depth. Concrete, 239(9), 79-82.

Xiaopeng, X., Danying, G., \& Jun, Z. (2006). Experimental research on mechanical performance of steel fiber reinforced concrete under the carbonation. Concrete, 197(6), 43-45.

Yanhua, G., \& Huimin, P. (2007). Study on carbonation of steel fiber reinforced concrete. Concrete, 208(2), 45-47.

Zhong-wei, W, \& Hui-zhen, L. (1999). High performance concrete. Beijing, China: China Railway Publishing House. 